\title{
O gênero Cosmarium Corda ex Ralfs (Desmidiaceae) no Reservatório de Itaipu, PR, Brasil
}

\author{
Viviane Costa de Menezes ${ }^{1,3}$, Norma Catarina Bueno ${ }^{1}$, Jascieli Carla Bortolini², Stefania Biolo² e \\ Natália Silveira Siqueira ${ }^{2}$
}

Recebido: 21.12.2010; aceito: 13.10.2011

\begin{abstract}
The genus Cosmarium Corda ex Ralfs (Desmidiaceae) in the Itaipu Reservoir, PR, Brazil). The study aimed to survey the flora of the Cosmarium genera on a tributary of Itaipu dam in western Paraná State. Samples were collected monthly from the biological community in five sampling stations in the limnetic region of the São Francisco Falso river tributary, Santa Helena, Paraná, between July 2003 and June 2004. Were used as criteria of occurrence of taxa in the samples constancies accidental, incidental and constant. The inventory resulted in the identification, description and illustration of 23 taxa, including 10 at the specific, 13 infraspecific level, and of these, seven varieties typical of their species and six varieties not typical of their species, and taxonomic two forms. The vast majority of taxa surveyed (69.5\%) had an accidental constancy, and the remaining species (30.5\%) represented by the constant accessory. There wasn't occurrence of constant taxa.
\end{abstract}

Key words: desmids, São Francisco Falso River, taxonomy

RESUMO - (O gênero Cosmarium Corda ex Ralfs (Desmidiaceae) no Reservatório de Itaipu, Paraná, Brasil). O trabalho objetivou o levantamento florístico do gênero Cosmarium em um tributário do Reservatório de Itaipu, na região Oeste do Paraná. Foram coletadas amostras mensais da comunidade biológica em cinco estações de amostragem na região limnética do tributário rio São Francisco Falso, Santa Helena, Paraná, entre julho de 2003 e junho de 2004. Utilizou-se como critérios de ocorrência dos táxons nas amostras as constâncias acidental, acessória e constante. O inventário resultou na identificação, descrição e ilustração de 23 táxons, sendo 10 em nível específico e 13 em nível infraespecíico, sendo destes, sete variedades típicas de suas espécies, seis variedades não típicas de suas espécies e duas formas taxonômicas. A grande maioria dos táxons inventariados $(69,5 \%)$ obteve uma constância acidental, sendo o restante das espécies $(30,5 \%)$ representado pela constância acessória. Não houve a ocorrência de táxons constantes.

Palavras-chave: desmídias, rio São Francisco Falso, taxonomia

\section{Introdução}

Pertencente ao grupo das desmídias, algas verdes microscópicas e cosmopolitas (Felisberto \& Rodrigues 2008), Cosmarium é um dos gêneros mais antigos e com maior número de táxons descritos (1.500) dentro da família Desmidiaceae (Bicudo \& Menezes 2006).

Entretanto, estudos taxonômicos envolvendo organismos desse gênero trazem dificuldades consideráveis aos pesquisadores da área, pois seus representantes podem ser facilmente confundidos com espécies pertencentes a Actinotaenium (Nägeli) Teiling, Penium Brébisson ex Ralfs,
Euastrum Ehrenberg ex Ralfs e Staurastrum Meyen (Bicudo \& Menezes 2006).

Dessa forma, características taxonômicas que permitam realizar uma correta identificação dos táxons devem ser levadas em consideração, dentre elas: morfologia celular, relação comprimento/largura, parede celular lisa ou com grânulos, e finalmente, vistas lateral e apical dos organismos (Felisberto \& Rodrigues 2004).

Apesar de serum grupo já há muito tempo estudado, são poucos os trabalhos taxonômicos que reportam à ocorrência de Cosmarium para o Estado do Paraná, podendo ser citados: Bittencourt-Oliveira (1993), que

1. Universidade Estadual do Oeste do Paraná, Programa de Pós-Graduação em Conservação e Manejo de Recursos Naturais, Rua Universitária 2069, Jardim Universitário, 85819-110 Cascavel, PR, Brasil

2. Universidade Estadual de Maringá, Programa de Pós-Graduação em Ecologia de Ambientes Aquáticos Continentais, Departamento de Biologia, Av. Colombo 5790, 87020-900 Maringá, PR, Brasil

3. Autor para correspondência: viviane_cmbio@hotmail.com 
estudou a comunidade fitoplanctônica do rio Tibagi, resultando na identificação de 15 táxons de Cosmarium. Nesse trabalho, entre as espécies encontradas para o reservatório de Itaipu, C. pachydermun Lundell, C. trilobulatum Reinsch var. abscissum (Schmidle) Krieger \& Gerloff e C. trilobulatum var. trilobulatum f. retusum Gutwinski foram primeiramente registradas para o Paraná; Cecy et al. (1997), que contribuíram com o estudo do fitoplâncton da represa do rio Passaúna, identificando um total de 15 táxons deste gênero; Picelli-Vicentim et al. (2001), que fizeram um levantamento do fitoplâncton também da represa do rio Passaúna e identificaram quatro táxons de Cosmarium e Felisberto \& Rodrigues (2008), que investigaram as espécies de três famílias de algas em particular, pertencentes à comunidade perifítica do reservatório de Salto do Vau - Bacia do rio Iguaçu, identificando um total de 17 táxons de Cosmarium e Felisberto \& Rodrigues (2010), que ao estudarem a ficoflórula perifítica do reservatório de Rosana, identificaram 48 táxons do gênero Cosmarium.

Para a região Oeste do Paraná há três contribuições, de um total de apenas sete trabalhos para todo o Estado. Silva \& Cecy (2004) analisaram as desmídias da área de abrangência da Usina Hidrelétrica de Salto Caxias, e das 20 espécies de Cosmarium encontradas, e que constam no inventário para o reservatório de Itaipu, C. formosulum Hoff in Nordstedt, C. impressulum Elfving var. impressulum, C. margaritatum (Lundell) Roy \& Bisset var. margaritatum f. minor (Boldt) West $\&$ West e C. porrectum Nordstedt foram primeiras citações para o Estado. Bortolini et al. (2010a) registraram 18 táxons deste gênero para o Lago Municipal de Cascavel. Finalmente Bortolini et al. (2010b) estudaram as desmídias do Rio São João, Parque Nacional do Iguaçu, identificando 11 táxons do gênero Cosmarium.

O presente trabalho teve como objetivo realizar o inventário taxonômico dos táxons pertencentes ao gênero Cosmarium em um tributário do reservatório de Itaipu, localizado na região Oeste do Paraná, bem como classificá-los de acordo com a sua constância nas amostras, além de apresentar a distribuição geográfica do gênero no Estado.

\section{Material e métodos}

O Reservatório de Itaipu localiza-se na divisa

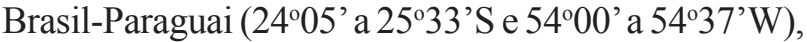
com uma área total de $170 \mathrm{~km}$ de extensão e $12 \mathrm{~km}$ de largura (Agostinho et al. 1999). O rio São Francisco
Falso, com $38,8 \mathrm{~km}^{2}$ de extensão, é o principal formador da área alagada do município de Santa Helena, no Oeste do Paraná (Biolo et al. 2008) (figura 1).

As amostragens foram realizadas mensalmente, de julho de 2003 a junho de 2004, em cinco estações de coleta ao longo do rio São Francisco Falso, totalizando 60 amostras. O material biológico foi coletado com rede de plâncton de malha de $25 \mu \mathrm{m}$ de abertura, e espremido de macrófitas aquáticas, sendo logo em seguida preservadas em solução Transeau (Bicudo \& Menezes 2006).

Para as análises qualitativas foram preparadas lâminas temporárias, em média 10 lâminas por amostra ou até não ocorrerem táxons diferentes. A análise das lâminas, biometria e ilustração dos táxons foram realizadas com microscópio binocular, com ocular micrometrada, acoplado a câmara clara, sempre no aumento de $1.000 \times$. Para a identificação dos táxons de Cosmarium foi utilizada como bibliografia base a obra de Prescott et al. (1981), além de artigos científicos da área. As amostras encontram-se depositadas no Herbário da Universidade Estadual do Oeste do Paraná (UNIOESTE), Campus Cascavel (UNOP). As medidas (em $\mu \mathrm{m}$ ) estão representadas pelos símbolos: compr. $=$ comprimento, larg. $=$ largura, istmo $=$ istmo.

Para inferir a constância de cada espécie nas amostras analisadas, utilizou-se o proposto por Dajoz (2005), onde $\mathrm{C}=(\mathrm{p} / \mathrm{P}) * 100$, sendo que: $\mathrm{C} \geq 50 \%$ representa as espécies constantes; $20 \leq \mathrm{C} \leq$ 50 representa as espécies acessórias; $\mathrm{C}<20 \%$ representa as espécies acidentais; $\mathrm{p}$ é o número de amostras contendo a espécie e $\mathrm{P}$ é o número total de amostras analisadas.

\section{Resultados e Discussão}

O inventário do gênero Cosmarium resultou na identificação, descrição e ilustração de 23 táxons, 10 em nível específico e 13 em nível infraespecífico, sendo destes, sete variedades típicas de suas espécies, seis variedades não típicas de suas espécies, e duas formas taxonômicas.

\section{ZYGNEMAPHYCEAE \\ DESMIDIALES \\ DESMIDIACEAE}

Cosmarium baileyi Wolle, Desm. U. S. : 64, pl. 16, figs. 17-18. 1884

= Cosmarium Depressum Bailey Smithson. Contrib. Knowledge 2 (Art. 8): 36, pl. 1, fig. 1. 1851.

Figura 2 


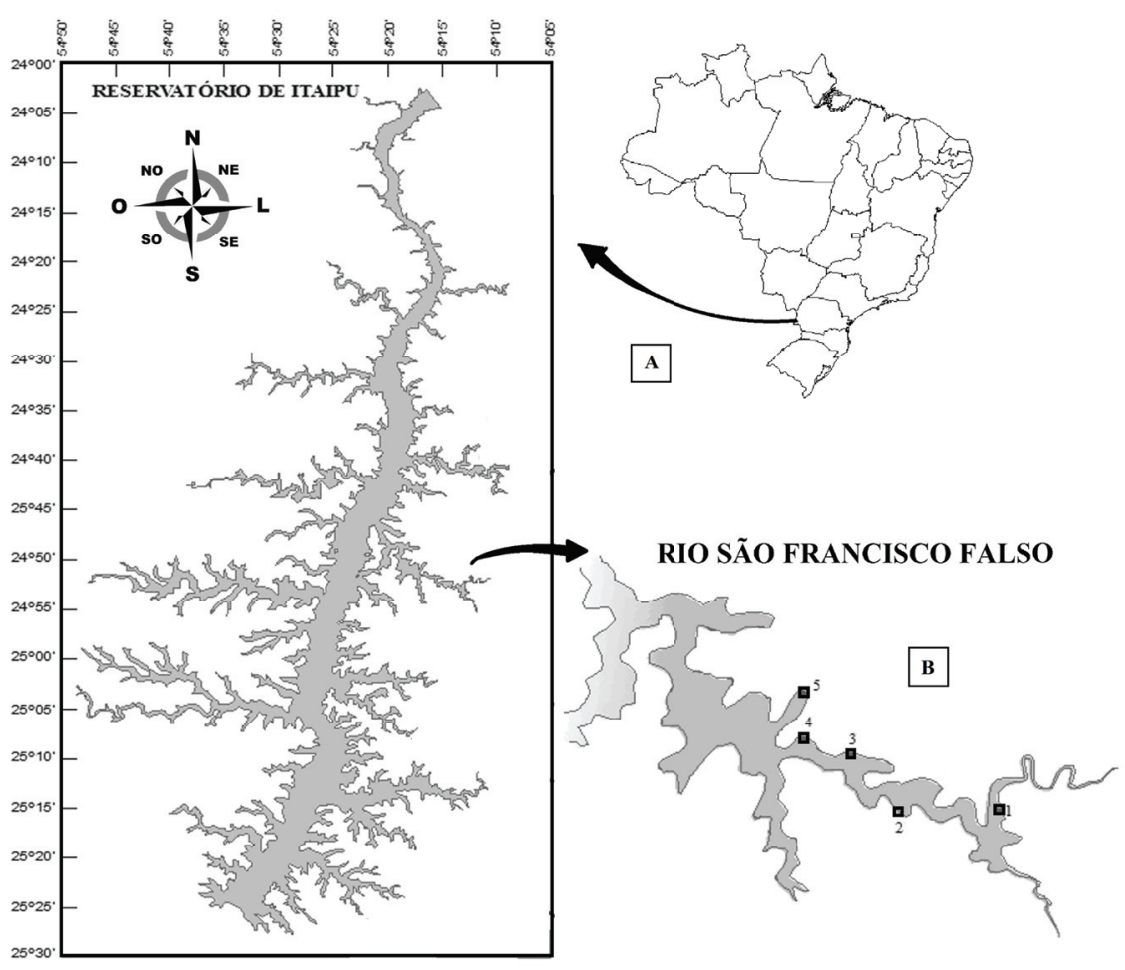

Figura 1. Mapa da área de estudo (a), Reservatório de Itaipu (b) localização das estações de coleta no rio São Francisco Falso, Paraná, Brasil. Fonte: Biolo et al. (2008), modificado.

Figure 1. Map of the study area (a), Itaipu Reservoir (b) location of the sampling station in the São Francisco Falso river, Paraná, Brazil. Source: Biolo et al. (2008), modified.

Célula quase tão longa quanto larga, $44,8 \mu \mathrm{m}$ compr., 43,2 $\mu \mathrm{m}$ larg., istmo 13,3 $\mu \mathrm{m}$. Constrição mediana profunda, seno fechado, semicélula subcircular a trapezoidal, ápice arredondado-truncado, parede celular finamente pontuada, 2 pirenóides por semicélula.

Material examinado: BRASIL. PARANÁ: Santa Helena, Reservatório de Itaipu, 1-VII-2003, F.R. Montrezol \& M.D. Daronch s.n. (UNOP1825).

Distribuição geográfica no Paraná: Reservatórios de Salto do Vau e Rosana (Felisberto \& Rodrigues 2005).

Constância: acidental.

Cosmarium contractum Kirchner in West \& G.S. West, Monogr. Brit. Desm. 2: 170. 1878

= Cosmarium contractum var. jacobsenii (Roy) West \& West, Monogr. 2: 171, pl. 61, fig. 26. 1905. Figura 3

Célula 1,2 vezes mais longa que larga, 25,4 $\mu \mathrm{m}$ compr., 19,7 $\mu \mathrm{m}$ larg., istmo 4,9 $\mu \mathrm{m}$. Constrição mediana profunda, seno aberto, semicélula oblonga, ápice levemente convexo, margens convexas, 1 pirenóide por semicélula.
Material examinado: BRASIL. PARANÁ: Santa Helena, Reservatório de Itaipu, 28-VII-2003, N.C. Bueno \& B. Tavares s.n. (UNOP1829).

Distribuição geográfica no Paraná: Represa do rio Passaúna (Cecy et al. 1997), rios da área de abrangência da Usina Hidrelétrica de Salto Caxias (Silva \& Cecy 2004) e comunidade perifítica do reservatório de Salto do Vau (Felisberto \& Rodrigues 2008).

Constância: acidental.

Cosmarium formosulum Hoff in Nordst., Vidensk. Medd. Naturh. Foren. Kjöbenhavn: 194, pl. 6, figs. 6-7. 1888.

Figura 4

Célula 1-1,1 vezes mais longa que larga, 31,5-34,9 $\mu \mathrm{m}$ compr., 27,4-29,4 $\mu \mathrm{m}$ larg., istmo $6,2-9,1 \mu \mathrm{m}$. Constrição mediana profunda, seno fechado, aberto na extremidade proximal, semicélula piramidal truncada, ápice truncado com 4-5 ondulações, margens laterais convexas, 6-7 ondulações bigranuladas, vista apical elíptica com 
margens laterais levemente infladas, parede celular com grânulos em séries radiais direcionadas à região mediana, 2 pirenóides por semicélula.

Material examinado: BRASIL. PARANÁ: Santa Helena, Reservatório de Itaipu, 1-VII-2003, F.R. Montrezol \& M.D. Daronch s.n. (UNOP1825).

Distribuição geográfica no Paraná: Rios da área de abrangência da Usina Hidrelétrica de Salto Caxias (Silva \& Cecy 2004) e Rio São João, Parque Nacional do Iguaçu (Bortolini et al. 2010b).

Constância: acidental.

Cosmarium galeritum Nordst. var. subtumidum Borge, Ark. f. Bot. 1: 95, pl. 3, fig. 14. 1903. Figura 5

Célula 1-1,6 vezes mais longa que larga, 43,9-50,4 $\mu \mathrm{m}$ compr., 43,2-48,3 $\mu \mathrm{m}$ larg., istmo 12,6-21 $\mu \mathrm{m}$. Constrição mediana profunda, seno fechado, semicélula piramidal-trapeziforme, ângulos basais arredondados, parede celular finamente pontuada, 2 pirenóides por semicélula.

Material examinado: BRASIL. PARANÁ: Santa Helena, Reservatório de Itaipu, 1-IX-2003, N.C. Bueno s.n. (UNOP1966); idem, 4-XI-2003, N.C. Bueno s.n. (UNOP2216); idem, 8-XII-2003, N.C. Bueno s.n. (UNOP2228).

Distribuição geográfica no Paraná: Reservatórios de Salto do Vau e Rosana (Felisberto \& Rodrigues 2005).

Constância: acidental.

Cosmarium granatum Bréb. ex Ralfs var. granatum, Brit. Desm.: 96, pl. 32, fig. 6. 1848. Figura 6

Célula 1,2-1,4 vezes mais longa que larga, 35,7-37,8 $\mu \mathrm{m}$ compr., 25,2-29,4 $\mu \mathrm{m}$ larg., istmo $6,3-10,5 \mu \mathrm{m}$. Constrição mediana profunda, seno fechado, semicélula piramidal-truncada, margens laterais convexas, ápice arredondado-truncado, margens lateral e apical lisas, ângulos basais e apicais arredondados, parede celular pontuada, presença de espessamento apical, vista lateral da semicélula elíptico-ovalada, 1 pirenóide por semicélula.

Material examinado: BRASIL. Paraná: Santa Helena, Reservatório de Itaipu, 8-XII-2003, N.C. Bueno s.n. (UNOP2228); idem, 5-IV-2004,
N.C. Bueno s.n. (UNOP2255); idem, 4-V-2004, N.C. Bueno \& P. Silveira s.n. (UNOP2262).

Distribuição geográfica no Paraná: Represa do Passaúna (Picelli-Vicentim et al. 2001), rios da área de abrangência da Usina Hidrelétrica de Salto Caxias (Silva \& Cecy 2004), reservatórios de Salto do Vau e Rosana (Felisberto \& Rodrigues 2005) e Lago Municipal de Cascavel (Bortolini et al. 2010a)

Constância: acidental.

Cosmarium impressulum Elfving var. impressulum, Acta Soc. Fauna Flora Fennica 2(2): 13, pl. 1, fig. 9. 1881

=Cosmarium meneghinii Bréb. f. reinschii Stvanffi, Notarisia: 2372. 1887.

Figura 7

Célula 1,1-1,3 vezes mais longa que larga, 24,7-35 $\mu \mathrm{m}$ compr., 18,5-31,5 $\mu \mathrm{m}$ larg., istmo 4,1-10,5 $\mu \mathrm{m}$. Constrição mediana profunda, seno fechado, semicélula semicircular, margens laterais convexas 4-5 onduladas, margem superior estreita 2-3 onduladas, parede celular lisa, 1 pirenóide por semicélula.

Material examinado: BRASIL. PARANÁ: Santa Helena, Reservatório de Itaipu, 1-VII-2003, F.R. Montrezol \& M.D. Daronch s.n. (UNOP1828); idem, 28-VII-2003, M.A.M. Soares s.n. (UNOP1833); idem, 1-IX-2003, N.C. Bueno \& B. Tavares s.n. (UNOP1963); idem, 1-IX-2003, N.C. Bueno \& B. Tavares s.n. (UNOP1966); idem, 6-X-2003, N.C. Bueno s.n. (UNOP2208); idem, 4-XI-2003, N.C. Bueno s.n. (UNOP2216); idem, 8-XII-2003, N.C. Bueno s.n. (UNOP2228); idem, 5-IV-2004, N.C. Bueno s.n. (UNOP2255).

Distribuição geográfica no Paraná: Rios da área de abrangência da Usina Hidrelétrica de Salto Caxias (Silva \& Cecy 2004) e reservatórios de Salto do Vau e Rosana (Felisberto \& Rodrigues 2005).

Constância: acessória.

Cosmarium lagoense Nordst. var. amoebum Förster \& Eckert in Förster, Hydrobiologia 23(3/4): 394, pl. 24, figs. 10-13. 1964.

Figura 8

Célula 1,1 vezes mais larga que longa, 33,6 $\mu \mathrm{m}$ compr., 37,8 $\mu \mathrm{m}$ larg., istmo $10,5 \mu \mathrm{m}$. Constrição mediana profunda, seno aberto, semicélula 
oval alongada, com um padrão de grânulos proeminentes na regiao central, margens laterais arredondadas, margem apical arredondada, mais elevada na região mediana e com espinhos curtos se estendendo até parte da margem lateral, 2 pirenóides por semicélula.

Material examinado: BRASIL. PARANÁ: Santa Helena, Reservatório de Itaipu, 4-XI-2003, N.C. Bueno s.n. (UNOP2216).

Distribuição geográfica no Paraná: Reservatórios de Salto do Vau e Rosana (Felisberto \& Rodrigues 2005).

Constância: acidental.

Cosmarium margaritatum (Lundell) Roy \& Bisset, Jour. Bot. 24: 194. $1886 \equiv$ Cosmarium latum Brébisson var. margaritatum Lundell, Nova Acta Soc. Reg. Sci. Upsaliensis 3, 8(2): 26. 1871. Figura 9

Célula 1-1,1 vezes mais longa que larga, 30,7-70,0 $\mu \mathrm{m}$ compr., 28,2-63,9 $\mu \mathrm{m}$ larg., istmo 8,3-18,9 $\mu \mathrm{m}$. Constrição mediana profunda, seno estreito fortemente dilatado na extremidade proximal, semicélula subretangular, ângulos arredondados, margens laterais convexas, ângulos superiores fortemente arredondados, parede celular uniformemente granulada, grânulos dispostos obliquamente, 2 pirenóides por semicélula.

Material examinado: BRASIL. PARANÁ: Santa Helena, Reservatório de Itaipu, 1-VII-2003, F.R. Montrezol \& M.D. Daronch s.n. (UNOP1825); idem, 1-VII-2003, F.R. Montrezol \& M.D. Daronch s.n. (UNOP1828); idem, 28-VII-2003, M.A.M. Soares s.n.(UNOP1831); idem, 6-X-2003, N.C. Bueno s.n. (UNOP2210); idem, 6-X-2003, N.C. Bueno s.n. (UNOP2211); idem, 4-XI-2003, N.C. Bueno s.n. (UNOP2216); idem, 8-XII-2003, N.C. Bueno s.n. (UNOP2232); idem, 3-II-2004, N.C. Bueno s.n. (UNOP2241); idem, 5-IV-2004, N.C. Bueno s.n. (UNOP2253); idem, 5-IV-2004, N.C. Bueno s.n. (UNOP2255); idem, 4-V-2004, N.C. Bueno \& P. Silveira s.n. (UNOP2262).

Distribuição geográfica no Paraná: Curitiba e arredores (Lozovei \& Luz 1976), estudo realizado em Curitiba (Lozovei \& Hohmann 1977), represa do rio Passaúna (Cecy et al. 1997), rios da área de abrangência da Usina Hidrelétrica de Salto Caxias (Silva \& Cecy 2004) e Rio São João, Parque Nacional do Iguaçu (Bortolini et al. 2010b).
Constância: acessória.

Cosmarium margaritatum (Lundell) Roy \& Bisset var. margaritatum f. minor (Boldt) West \& West, Jour. Bot., 35: 121. 1897.

Figura 10

Célula tão comprida quanto larga ou 1,1 vezes mais comprida que larga, 31,5-39,9 $\mu \mathrm{m}$ compr., 33,6-37,8 $\mu \mathrm{m}$ larg., istmo 8,4-10,5 $\mu \mathrm{m}$. Constrição mediana profunda, seno mediano fechado dilatado na extremidade proximal, semicélula oblonga, margens lateral e apical convexas e crenuladas, ângulos basais e apicais arredondados, parede celular granulosa, com séries de grânulos densos, dispostos obliquamente, pontuações ordenadas contornando os grânulos, 2 pirenóides por semicélula.

Material examinado: BRASIL. PARAnÁ: Santa Helena, Reservatório de Itaipu, 4-XI-2003, N.C. Bueno s.n. (UNOP2216); idem, 19-I-2004, N.C. Bueno s.n. (UNOP2238); idem, 5-IV-2004, N.C. Bueno s.n. (UNOP2251); idem, 17-VI-2004, N.C. Bueno \& P. Silveira s.n. (UNOP2263).

Distribuição geográfica no Paraná: Rios da área de abrangência da Usina Hidrelétrica de Salto Caxias (Silva \& Cecy 2004), reservatórios de Salto do Vau e Rosana (Felisberto \& Rodrigues 2005) e Lago Municipal de Cascavel (Bortolini et al. 2010a).

Constância: acidental.

Cosmarium naegelianum Bréb., Mém. Soc. Impér. Sci. Nat. Cherbourg 4: 127. 1856.

Figura 11

Célula $1-1,1$ vezes mais longa que larga, 18,6-26,8 $\mu \mathrm{m}$ compr., 17-22,7 $\mu \mathrm{m}$ larg., istmo 4,1-6,2 $\mu \mathrm{m}$. Constrição mediana profunda, seno fechado, semicélula piramidal-truncada, ápice truncado, margens laterais 3-4 onduladas, margem apical 3-4 onduladas, parede celular pontuada, cloroplasto axial, 1 pirenóide por semicélula.

Material examinado: BRASIL. PARANÁ: Santa Helena, Reservatório de Itaipu, 1-VII-2003, F. Montrezol \& M. Daronch s.n. (UNOP1825); idem, 1-IX-2003, N.C. Bueno \& B. Tavares s.n. (UNOP1962); idem, 1-IX-2003, N.C. Bueno \& B. Tavares s.n. (UNOP1966); idem, 10-III-2004, N.C. Bueno s.n. (UNOP2245).

Distribuição geográfica no Paraná: Reservatórios de 

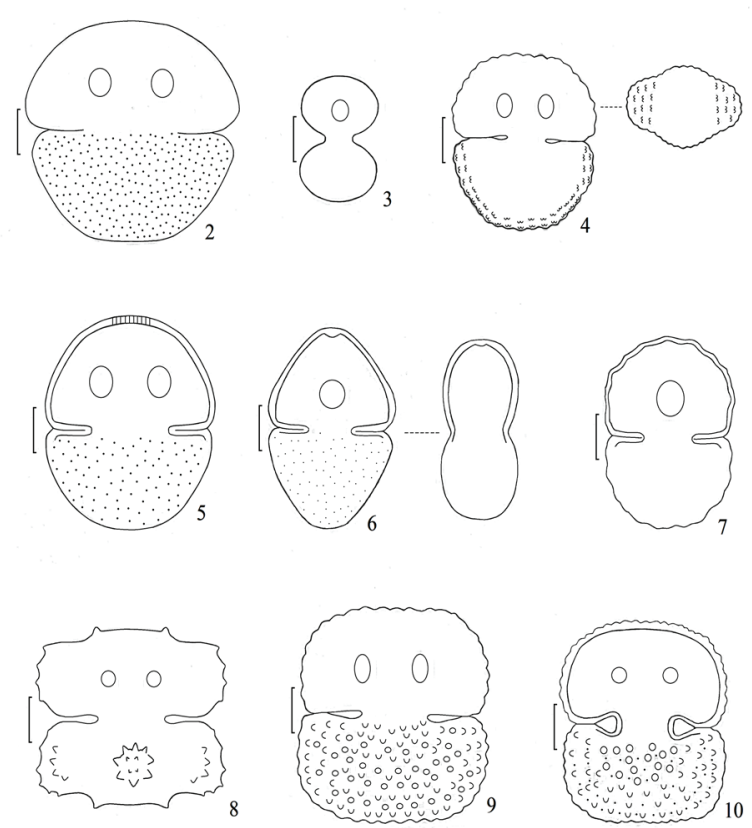

Figuras 2-10. Espécies de Cosmarium do Reservatório de Itaipu. 2. Cosmarium baileyi. 3. C. contractum. 4. C. formosulum.

5. C. galeritum var. subtumidum. 6. C. granatum var. granatum.

7. C. impressulum var. impressulum. 8. C. lagoense var. amoebum.

9. C. margaritatum. 10. C. margaritatum var. margaritatum.

f. minor. Barras de escala $=10 \mu \mathrm{m}$.

Figures 2-10. Species of Cosmarium from Itaipu Reservoir. Cosmarium baileyi. 3. C. contractum. 4. C. formosulum. 5. C. galeritum var. subtumidum. 6. C. granatum var. granatum. 7. C. impressulum var. impressulum. 8. C. lagoense var. amoebum. 9. C. margaritatum. 10. C. margaritatum var. margaritatum. f. minor. Scale bars $=10 \mu \mathrm{m}$.

Salto do Vau e Rosana (Felisberto \& Rodrigues 2005).

Constância: acidental.

Cosmarium pachydermum Lundell, Nova Acta Reg.

Soc. Sci. Upsaliensis 3, 8(2): 39, pl. 2, fig. 15. 1871. Figura 12

Célula 1,1 vezes mais longa que larga, 30,7-83,8 $\mu \mathrm{m}$ compr., 26,6-74,7 $\mu \mathrm{m}$ larg., istmo 11,6-39,9 $\mu \mathrm{m}$. Constrição mediana moderadamente fechada, seno fechado, aberto na região proximal, semicélula semicircular, ângulos basais fortemente arredondados, ápice arredondado, parede celular finamente pontuada, 2 pirenóides por semicélula.

Material examinado: BRASIL. PARANÁ: Santa Helena, Reservatório de Itaipu, 1-VII-2003, F.R. Montrezol \& M.D. Daronch s.n. (UNOP1825); idem, 28-VII-2003, F.R. Montrezol \& M.D. Daronch s.n. (UNOP1830); idem, 1-IX-2003,
N.C. Bueno \& B. Tavares s.n. (UNOP1963); idem, 4-XI-2003, N.C. Bueno s.n. (UNOP2214).

Distribuição geográfica no Paraná: Rio Tibagi (Bittencourt-Oliveira 1993) e Lago Municipal de Cascavel (Bortolini et al. 2010a).

Constância: acidental

Cosmarium porrectum Nordst., Vidensk. Medd. Naturh. Foren. Kjöbenha 21:207, pl. 3, fig. 28. 1870. Figura 13

Célula 1-1,2 vezes mais larga que longa, 49,8-71,4 $\mu \mathrm{m}$ compr., 63,9-77,7 $\mu \mathrm{m}$ larg., istmo 18,5-23,8 $\mu \mathrm{m}$. Constrição mediana profunda, seno fechado, aberto na região proximal, semicélula subtrapeziforme, ângulos basais arredondados, margens laterais retusas divergindo para cima, ápice retuso, parede celular granulosa, com série de grânulos densos, proeminentes, dispostos obliquamente, contornados por pequenas pontuações, 2 pirenóides por semicélula.

Material examinado: BRASIL. PARANÁ: Santa Helena, Reservatório de Itaipu, 1-VII-2003, F.R. Montrezol \& M.D. Daronch s.n. (UNOP1828); idem, 28-VII-2003, M.A.M. Soares s.n. (UNOP1833); idem, 4-XI-2003, N.C. Bueno s.n. (UNOP2216); idem, 8-XII-2003, N.C. Bueno s.n. (UNOP2232); idem, 3-II-2004, N.C. Bueno s.n. (UNOP2240); idem, 3-II-2004, N.C. Bueno s.n. (UNOP2243); idem, 10-III-2004, N.C. Bueno s.n. (UNOP2248); idem, 5-IV-2004, N.C. Bueno s.n. (UNOP2251).

Distribuição geográfica no Paraná: Rios da área de abrangência da Usina Hidrelétrica de Salto Caxias (Silva \& Cecy 2004) e reservatórios de Salto do Vau e Rosana (Felisberto \& Rodrigues 2005).

Constância: acessória.

Cosmarium pseudoconnatum Nordst., Vidensk. Medd. Naturh. Foren. Kjöbenhavn 21: 214, pl. 3, fig. 17. 1870.

Figura 14

Célula 1-1,2 vezes mais longa que larga, 29,9-57,7 $\mu \mathrm{m}$ compr., 29,9-45,3 $\mu \mathrm{m}$ larg., istmo 24,9-34 $\mu \mathrm{m}$. Constrição mediana rasa, seno mediano amplamente raso, semicélula semielíptica, ângulos basais arredondados, parede celular finamente pontuada, 4 pirenóides por semicélula. 
Material examinado: BRASIL. ParanÁ: Santa Helena, Reservatório de Itaipu, 1-VII-2003, F.R. Montrezol \& M.D. Daronch s.n. (UNOP1825); idem, 1-VII-2003, F.R. Montrezol \& M.D. Daronch s.n. (UNOP1829); idem, 28-VII-2003, F. Montrezol \& M. Daronch s.n. (UNOP1830); idem, 28-VII-2003, F.R. Montrezol \& M.D. Daronch s.n. (UNOP1831); idem, 28-VII-2003, F.R. Montrezol \& M.D. Daronch s.n. (UNOP1833); idem, 1-IX-2003, N.C. Bueno \& B. Tavares s.n. (UNOP1962); idem, 6-X-2003, N.C. Bueno s.n. (UNOP2208); idem, 6-X-2003, N.C. Bueno s.n. (UNOP2209); idem, 6-X-2003, N.C. Bueno s.n. (UNOP2212); idem, 4-XII-2003, N.C. Bueno s.n. (UNOP2216); idem, 8-XII-2003, N.C. Bueno s.n. (UNOP2232); idem, 10-III-2004, N.C. Bueno s.n. (UNOP 2245); idem, 10-III-2004, N.C. Bueno s.n. (UNOP2252).

Distribuição geográfica no Paraná: Rio Tibagi (Bitttencourt-Oliveira 1993), represa do rio Passúna (Cecy et al. 1997), fitoplâncton da represa do Passaúna (Picelli-Vicentim et al. 2001), rios da área de abrangência da Usina Hidrelétrica de Salto Caxias (Silva \& Cecy 2004), reservatório de Salto do Vau e Rosana (Felisberto \& Rodrigues 2005), comunidade perifítica do reservatório de Salto do Vau (Felisberto \& Rodrigues 2008) e Rio São João, Parque Nacional do Iguaçu (Bortolini et al. 2010b).

Constância: acessória.

Cosmarium quadrum Lundell var. quadrum, Nova Acta Reg. Soc. Sci. Upsaliensis 3, 8(2): 25, pl. 2, fig. 11. 1871.

Figura 15

Célula 1-1,2 vezes mais larga que longa, 26,8-82,4 $\mu \mathrm{m}$ compr., 28,8-86,5 $\mu \mathrm{m}$ larg., istmo 6,2-20,6 $\mu \mathrm{m}$. Constrição mediana profunda, seno fechado, aberto na extremidade proximal, semicélula subretangular, ângulos basais arredondados, margens laterais convexas, ápice geralmente retuso, algumas vezes truncado, parede celular densamente granulosa, grânulos distribuídos obliquamente em série, 2 pirenóides por semicélula.

Material examinado: BRASIL. PARANÁ: Santa Helena, Reservatório de Itaipu, 1-VII-2003, F.R. Montrezol \& M.D. Daronch s.n. (UNOP1825); idem, 1-VII-2003, F.R. Montrezol \& M.D. Daronch s.n. (UNOP1828); idem, 28-VII-2003, F.R. Montrezol \& M.D. Daronch s.n.
(UNOP1830); idem, 28-VII-2003, F.R. Montrezol \& M.D. Daronch s.n. (UNOP1831); idem, 28-VII-2003, F.R. Montrezol \& M.D. Daronch s.n. (UNOP1833); idem, 1-IX-2003, N.C. Bueno \& B. Tavares s.n. (UNOP1962); idem, 1-IX-2003, N.C. Bueno \& B. Tavares s.n. (UNOP1963); idem, 1-IX-2003, N.C. Bueno \& B. Tavares s.n. (UNOP1966); idem, 6-X-2003, N.C. Bueno s.n. (UNOP2210); idem, 6-X-2003, N.C. Bueno s.n. (UNOP2211); idem, 4-XI-2003, N.C. Bueno s.n. (UNOP2214); idem, 4-XII-2003, N.C. Bueno s.n. (UNOP2216); idem, 8-XII-2003, N.C. Bueno s.n. (UNOP2230); idem, 8-XII-2003, N.C. Bueno s.n. (UNOP2232); idem, 3-II-2004, N.C. Bueno s.n. (UNOP2240); idem, 3-II-2004, N.C. Bueno s.n. (UNOP2243); idem, 10-III-2004, N.C. Bueno s.n. (UNOP2246); idem, 10-III-2004, N.C. Bueno s.n. (UNOP2247); idem, 10-III-2004, N.C. Bueno s.n. (UNOP2248); idem, 4-V-2004, N.C. Bueno \& P. Silveira s.n. (UNOP2259); idem, 4-V-2004, N.C. Bueno \& P. Silveira s.n. (UNOP2261); idem, 4-V-2004, N.C. Bueno \& P. Silveira s.n. (UNOP2262); idem, 17-VI-2004, N.C. Bueno \& P. Silveira s.n. (UNOP2263).

Distribuição geográfica no Paraná: Represa do rio Passaúna (Cecy et al. 1997).

Constância: acessória.

Cosmarium quadrum var. minus Nordst., Acta Univ. Lund. 9: 11. 1873.

Figura 16

Célula 1-1,1 vezes mais longa que larga, 48, $1 \mu \mathrm{m}$ compr., 46,1 $\mu \mathrm{m}$ larg., istmo 14,9 $\mu \mathrm{m}$. Constrição mediana profunda, seno fechado, aberto na extremidade proximal, semicélulas subretangulares, ângulos arredondados, margem lateral convexa, margem apical levemente convexa, vista lateral subcircular, parede celular granulosa, 2 pirenóides por semicélula.

Material examinado: BRASIL. PARANÁ: Santa Helena, Reservatório de Itaipu, 1-VII-2003, F.R. Montrezol \& M.D. Daronch s.n. (UNOP1825); idem, 5-IV-2004, N.C. Bueno s.n. (UNOP2253).

Distribuição geográfica no Paraná: Reservatórios de Salto do Vau e Rosana (Felisberto \& Rodrigues 2005) e Lago Municipal de Cascavel (Bortolini et al. 2010a).

Constância: acidental. 
Cosmarium quadrum var. sublatum (Nordst.) West \& West, Monogr. Brit. Desmid. 4: 21. 1912.

Figura 17

Célula 1,1-1,2 vezes mais larga que longa, 65,9-86,5 $\mu \mathrm{m}$ compr., 76,2-94,8 $\mu \mathrm{m}$ larg., istmo 18,5-24,9 $\mu \mathrm{m}$. Constrição mediana profunda, seno fechado, amplamente aberto na extremidade proximal, margens laterais convexas, margem apical retusa, parede celular densamente granulosa, dispostas obliquamente, 2 pirenóides por semicélula.

Material examinado: BRASIL. PARANÁ: Santa Helena, Reservatório de Itaipu, 1-VII-2003, F.R. Montrezol \& M.D. Daronch s.n. (UNOP1825); idem, 1-VII-2003, F.R. Montrezol \& M.D. Daronch s.n. (UNOP1828); idem, 28-VII-2003, F.R. Montrezol \& M.D. Daronch s.n. (UNOP1833); idem, 1-IX-2003, N.C. Bueno \& B. Tavares s.n. (UNOP1963); idem, 6-X-2003, N.C. Bueno s.n. (UNOP2208); idem, 6-X-2003, N.C. Bueno s.n. (UNOP2211); idem, 4-XII-2003, N.C. Bueno s.n. (UNOP2216); idem, 8-XII-2003, N.C. Bueno s.n. (UNOP2229); idem, 8-XII-2003, N.C. Bueno s.n. (UNOP2232); idem, 3-II-2004, N.C. Bueno s.n. (UNOP2240); idem, 3-II-2004, N.C. Bueno s.n. (UNOP2243); idem, 10-III-2004, N.C. Bueno s.n. (UNOP2248); idem, 4-V-2004, N.C. Bueno \& P. Silveira s.n. (UNOP2262).

Distribuição geográfica no Paraná: Reservatórios de Salto do Vau e Rosana (Felisberto \& Rodrigues 2005).

Constância: acessória.

Cosmarium regnellii Wille, Bih. Kongl. Svenska Vet.Akad. Handl. 8(18): 16, pl. 1, fig. 34. 1884.

Figura 18

Célula 1,1 vezes mais longa que larga ou tão longa quanto larga, 14,7-20,6 $\mu \mathrm{m}$ compr., 12,6-20,6 $\mu \mathrm{m}$ larg., istmo 2,1-8,2 $\mu \mathrm{m}$. Constrição mediana profunda, seno fechado, semicélula trapezóide-hexagonal, margens laterais lisas com uma pequena projeção em cada margem, margens convergindo abruptamente para o ápice, ângulos basais e apicais arredondados e ápice amplamente truncado, parede celular lisa, cloroplasto com 1 pirenóide por semicélula.

Material examinado: BRASIL. PARANÁ: Santa Helena, Reservatório de Itaipu, 1-IX-2003, N.C. Bueno \& B. Tavares s.n. (UNOP1963); idem, 6-X-2003, N.C. Bueno s.n. (UNOP2208); idem, 8-XII-2003, N.C. Bueno s.n. (UNOP2232).
Distribuição geográfica no Paraná: Reservatórios de Salto do Vau e Rosana (Felisberto \& Rodrigues 2005), comunidade perifítica do reservatório de Salto do Vau (Felisberto \& Rodrigues 2008) e Lago Municipal de Cascavel (Bortolini et al. 2010a).

Constância: acidental.

Cosmarium reniforme var. compressum Nordst., Bot. Notiser : 159. 1887.

Figura 19

Célula 1,1-1,2 vezes mais longa que larga, 45,3-61,4 $\mu \mathrm{m}$ compr., 41,2-49,9 $\mu \mathrm{m}$ larg., istmo 12,4-15,6 $\mu \mathrm{m}$. Constrição mediana profunda, seno fechado, pouco dilatado na região proximal, semicélula reniforme, margem lateral convexa, vista lateral oblonga, parede celular granulosa, grânulos dispostos obliquamente, 2 pirenóides por semicélula.

Material examinado: BRASIL. PARANÁ: Santa Helena, Reservatório de Itaipu, 1-IX-2003, N.C. Bueno \& B. Tavares s.n. (UNOP1962).

Distribuição geográfica no Paraná: Reservatórios de Salto do Vau e Rosana (Felisberto \& Rodrigues 2005).

Constância: acidental.

Cosmarium subspeciosum Nordst. var. subspeciosum Öfv., Kongl. Vet.-Akad. Förhandl. 32(6): 22, pl. 6, fig. 13. 1875.

Figura 20

Célula 1,3-1,4 vezes mais longa que larga, 48,3-52,5 $\mu \mathrm{m}$ compr., 33,6-37,8 $\mu \mathrm{m}$ larg., istmo 8,2-12,6 $\mu \mathrm{m}$. Constrição mediana profunda, seno fechado, semicélula semicircular a piramidal, margens laterais com 5-7 crenulações bigranuladas, margem apical com 4-5 crenulações, vista apical oblonga, com pólos amplamente arredondados, com uma inflação na região mediana em ambos os lados, parede celular granulosa com pares de grânulos em séries radiais, 2 pirenóides por semicélula.

Material examinado: BRASIL. Parané: Santa Helena, Reservatório de Itaipu, 28-VII-2003, M.A.M. Soares s.n. (UNOP1831); idem, 28-VII-2003, M.A.M. Soares s.n. (UNOP1832); idem, 8-XII-2003, N.C. Bueno s.n. (UNOP2230); idem, 17-VI-2004, N.C. Bueno \& P. Silveira s.n. (UNOP2263).

Distribuição geográfica no Paraná: Reservatórios de Salto do Vau e Rosana (Felisberto \& Rodrigues 2005), comunidade perifítica do reservatório de Salto do Vau 
(Felisberto \& Rodrigues 2008) e Lago Municipal de Cascavel (Bortolini et al. 2010a).

Constância: acidental.

\section{Cosmarium trilobulatum Reinsch var. trilobulatum,}

Acta Soc. Senckenberg 6: 118(10), pl. 22(3) A II, fig. 1-6. 1867.

Figura 21

Célula 1,2-1,3 vezes mais longa que larga, 18,5-24,7 $\mu \mathrm{m}$ compr., 14,4-20,6 $\mu \mathrm{m}$ larg., istmo 4,1-8,2 $\mu \mathrm{m}$. Constrição mediana profunda, seno fechado, semicélula trilobulada, margens laterais convergentes, levemente retusas na parte média, margem apical amplamente truncada, retusa na parte média, parede celular finamente pontuada, 1 pirenóide por semicélula.
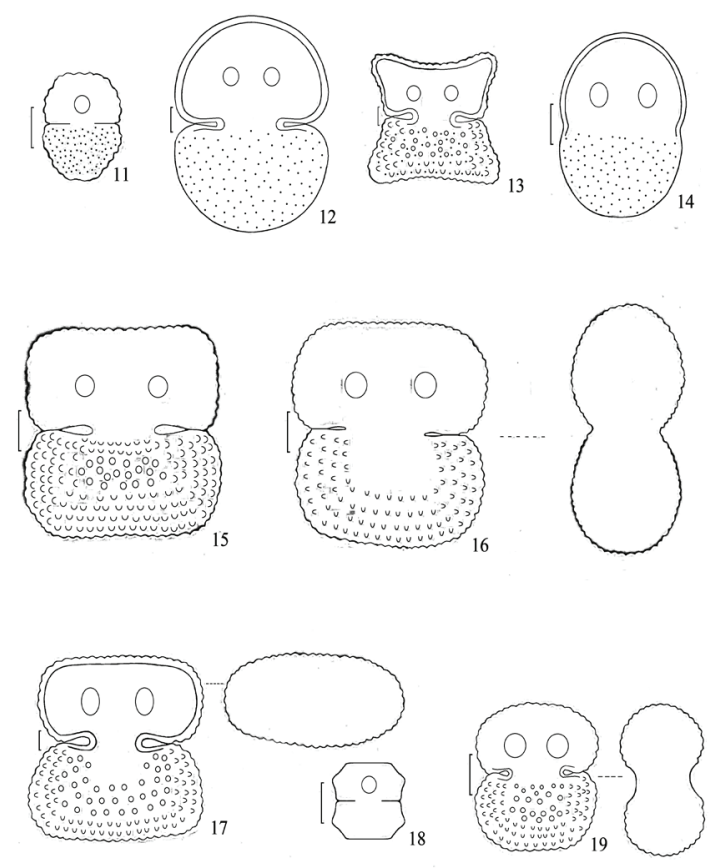

Figuras 11-19. Espécies de Cosmarium do Reservatório de Itaipu. 11. Cosmarium naegelianum. 12. C. pachydermum. 13. C. porrectum. 14. C. pseudoconnatum. 15. C. quadrum var. quadrum. 16. C. quadrum var. minus. 17. C. quadrum var. sublatum. 18. C. regnellii. 19. C. reniforme var. compressum. Barras de escala $=10 \mu \mathrm{m}$.

Figures 11-19. Species of Cosmarium from Itaipu Reservoir. 11. Cosmarium naegelianum. 12. C. pachydermum. 13. C. porrectum. 14. C. pseudoconnatum. 15. C. quadrum var. quadrum. 16. C. quadrum var. minus. 17. C. quadrum var. sublatum. 18. C. regnellii. 19. C. reniforme var. compressum. Scale bars $=10 \mu \mathrm{m}$.
Material examinado: BRASIL. PARANÁ: Santa Helena, Reservatório de Itaipu, 28-VII-2003, F.R. Montrezol \& M.D. Daronch s.n. (UNOP1830); idem, 28-VII-2003, F.R. Montrezol \& M.D. Daronch s.n. (UNOP1833); idem, 1-IX-2003, N.C. Bueno \& B. Tavares s.n. (UNOP1962); idem, 1-IX-2003, N.C. Bueno \& B. Tavares s.n. (UNOP1963); idem, 4-V-2004, N.C. Bueno \& P. Silveira s.n. (UNOP2262).

Distribuição geográfica no Paraná: Rio Tibagi (Bittencourt-Oliveira 1993), reservatórios de Salto do Vau e Rosana (Felisberto \& Rodrigues 2005) Lago Municipal de Cascavel (Bortolini et al. 2010a) e Rio São João, Parque Nacional do Iguaçu (Bortolini et al. 2010b).

Constância: acidental.

\section{Cosmarium trilobulatum var. trilobulatum f. retusum}

Gutw., Spraw. Komisyi fizyogr. Akad. Umiej. w Krakowie 2: 27, pl. 1, fig. 16. $1892 \equiv$ Cosmarium trilobulatum f. retusa Reinsch in Wade, Disser.: 217, pl. 16, fig. 8. 1952.

\section{Figura 22}

Célula 1,2-1,3 vezes mais longa que larga, 18,3-26,6 $\mu \mathrm{m}$ compr., 14,1-20,6 $\mu \mathrm{m}$ larg., istmo $4,1-5,8 \mu \mathrm{m}$. Constrição mediana profunda, seno mediano fechado, semicélula trilobulada, conjunto dos lobos basais transversalmente retangular, ângulos basais retos, amplamente arredondados, margens laterais e ápices das semicélulas retuso, parede celular lisa, 1 pirenóide por semicélula.

Material examinado: BRASIL. PARANÁ: Santa Helena, Reservatório de Itaipu, 1-VII-2003, F.R. Montrezol \& M.D. Daronch s.n. (UNOP1825); idem, 1-IX-2003, N.C. Bueno \& B. Tavares s.n. (UNOP1962).

Distribuição geográfica no Paraná: Rio Tibagi (Bittencourt-Oliveira 1993).

Constância: acidental.

Cosmarium trilobulatum Reinsch var. abscissum (Schmidle) Krieg. \& Gerloff, Die Gattung Cosmarium 1:99, pl. 21, fig. 1. $1962 \equiv$ Cosmarium hammeri Reinsch f. abcissa Schmidle, Hedwigia 34(2): 302, pl. 4, fig. 8. 1895.

Figura 23

Célula 1,1-1,3 vezes mais longa que larga, 
20,6-30,3 $\mu \mathrm{m}$ compr., 18,5-22,7 $\mu \mathrm{m}$ larg., istmo 4,1-7,4 $\mu \mathrm{m}$. Contrição mediana profunda, seno fechado, semicélula trilobulada, ápice amplamente truncado, margens laterais arredondadas até a região mediana, após, levemente côncava até o ápice, parede celular finamente pontuada, 1 pirenóide por semicélula.

Material examinado: BRASIL. PARANÁ: Santa Helena, Reservatório de Itaipu, 28-VII-2003, N.C. Bueno s.n. (UNOP1829); idem, 1-IX-2003, N.C. Bueno \& B. Tavares s.n. (UNOP1966); idem, 6-X-2003, N.C. Bueno s.n. (UNOP2208); idem, 4-XII-2003, N.C. Bueno s.n. (UNOP2216); idem, 5-IV-2004, N.C. Bueno s.n. (UNOP2253); idem, 4-V-2004, N.C. Bueno \& P. Silveira s.n. (UNOP2262).

Distribuição geográfica no Paraná: Rio Tibagi (Bitttencourt-Oliveira 1993) e rios da área de abrangência da Usina Hidrelétrica de Salto Caxias (Silva \& Cecy 2004).

Constância: acidental.

Cosmarium vexatum West, Jour. Roy. Microsc. Soc. 1892: 727, pl. 9, fig. 33. 1892a.

Figura 24

Célula 1,1-1,2 vezes mais longa que larga, 28,8-43,2 $\mu \mathrm{m}$ compr., 22,7-37,7 $\mu \mathrm{m}$ larg., istmo $6,2-12,4 \mu \mathrm{m}$. Constrição mediana profunda, seno fechado, ligeiramente aberto na extremidade proximal, semicélula piramidal-truncada, ângulos arredondados, margens laterais convexas 5-6 onduladas, ápice truncado, 3-4 onduladas, parede celular pontuada, 2 pirenóides por semicélula.

Material examinado: BRASIL. PARANÁ: Santa Helena, Reservatório de Itaipu, 1-VII-2003, F.R. Montrezol \& M.D. Daronch s.n. (UNOP1825); idem, 1-VII-2003, N.C. Bueno \& B. Tavares s.n. (UNOP1829); idem, 28-VII-2003, F.R. Montrezol \& M.D. Daronch s.n. (UNOP1830); idem, 28-VII-2003, F.R. Montrezol \& M.D. Daronch s.n. (UNOP1831); idem, 1-IX-2003, N.C. Bueno \& B. Tavares s.n. (UNOP1962); idem, 1-IX-2003, N.C. Bueno \& B. Tavares s.n. (UNOP1963); idem, 6-X-2003, N.C. Bueno s.n. (UNOP2208); idem, 6-X-2003, N.C. Bueno s.n. (UNOP2209); idem, 8-XII-2003, N.C. Bueno s.n. (UNOP2228); idem, 8-XII-2003, N.C. Bueno s.n. (UNOP2230); idem, 8-XII-2003, N.C. Bueno s.n. (UNOP2232); idem, 10-III-2004, N.C. Bueno s.n. (UNOP2246); idem,
5-IV-2004, N.C. Bueno s.n. (UNOP2252); idem, 5-IV-2004, N.C. Bueno s.n. (UNOP2253); idem, 5-IV-2004, N.C. Bueno s.n. (UNOP2255); idem, 4-V-2004, N.C. Bueno \& P. Silveira s.n. (UNOP2261); idem, 17-VI-2004, N.C. Bueno \& P. Silveira s.n. (UNOP2263).

Distribuição geográfica no Paraná: Reservatórios de Salto do Vau e Rosana (Felisberto \& Rodrigues 2005), comunidade perifítica do reservatório de Salto do Vau (Felisberto \& Rodrigues 2008) e Rio São João, Parque Nacional do Iguaçu (Bortolini et al. 2010b).

Constância: acessória.

O levantamento taxonômico do gênero Cosmarium para o reservatório de Itaipu resultou na identificação de 23 táxons, sendo $69,5 \%$ deles representados por espécies acidentais e 30,5\% por espécies acessórias, por outro lado nenhuma espécie foi constante, ou seja, ocorrendo em mais de $50 \%$ das amostras analisadas.

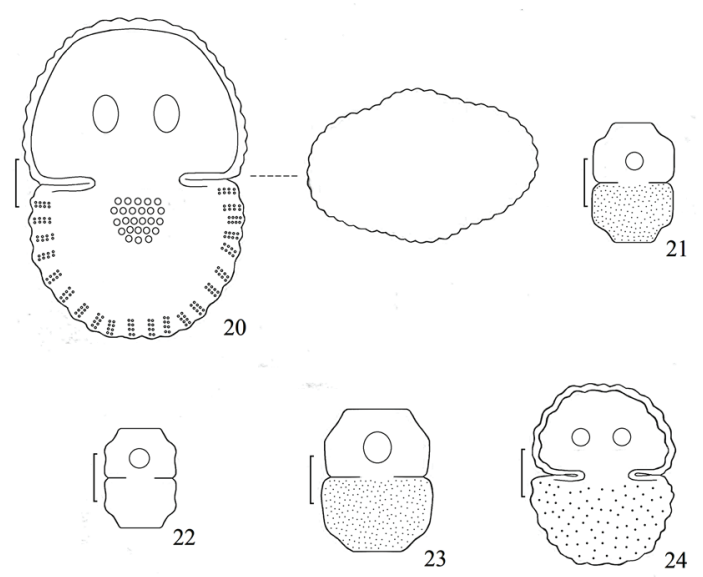

Figuras 20-24. Espécies de Cosmarium do Reservatório de Itaipu. 20. Cosmarium subspeciosum var. subspeciosum. 21. C. trilobulatum var. trilobulatum. 22. C. trilobulatum var. trilobulatum f. retusum. 23. C. trilobulatum var. abscissum. 24. C. vexatum. Barras de escala $=10 \mu \mathrm{m}$.

Figures 20-24. Species of Cosmarium from Itaipu Reservoir. 20. Cosmarium subspeciosum var. subspeciosum. 21. C. trilobulatum var. trilobulatum. 22. C. trilobulatum var. trilobulatum f. retusum. 23. C. trilobulatum var. abscissum. 24. $C$. vexatum. Scale bars $=10 \mu \mathrm{m}$.

Cosmarium quadrum var. quadrum apesar de estar classificada como uma espécie acessória, foi a que apresentou maior constância (45\%), entretanto a única citação deste táxon para o Estado do Paraná encontra-se no trabalho realizado por Cecy et al. (1997) na represa do rio Passaúna, o que 
salienta a necessidade de que mais estudos acerca da flora ficológica paranaense sejam realizados, contribuindo assim com o conhecimento a respeito da distribuição geográfica deste gênero no Paraná.

Finalmente, o reservatório de Itaipu em toda a sua extensão, constitui um importante ambiente aquático para a região, uma vez que abriga uma das mais importantes Usinas Hidrelétricas do mundo, apesar disso, apenas o trabalho de Biolo et al. (2008) havia sido publicado para este resevatório até o momento.

\section{Agradecimentos}

As autoras agradecem à Coordenação de Aperfeiçoamento de Pessoal de Nível Superior (CAPES) pelo apoio financeiro cedido à primeira autora por meio da concessão de bolsa de mestrado.

\section{Literatura citada}

Agostinho, A.A., Okaeda, E.K. \& Gregoris, J. 1999. A pesca no reservatório de Itaipu: Aspectos socioeconômicos e impactos do represamento. In: R. Henry (ed.). Ecologia de reservatórios: Estrutura, função e aspectos sociais. FAPESP, FUNDIBIO, Botucatu, pp. 279-320.

Bicudo, C.E.M. \& Menezes, M. 2006. Gêneros de algas de águas continentais do Brasil: chave para identificação e descrições. RiMa, São Carlos.

Biolo, S., Siqueira, N.S. \& Bueno, N.C. 2008. Desmidiaceae (exceto Cosmarium) de um tributário do Reservatório de Itaipu, Paraná, Brasil. Hoehnea 35: 309-326.

Bittencourt-Oliveira, M.C. 1993. Ficoflórula do Rio Tibagi, Estado do Paraná, Brasil III: gêneros Actinotaenium, Cosmarium e Staurodesmus (Zygnemaphyceae). Semina, Ciências Biológicas 14: 86-95.

Bortolini, J.C., Bueno, N.C., Moresco, C., Biolo, S. \& Siqueira, N.S. 2010a. Cosmarium Corda ex Ralfs (Desmidiaceae) em um lago artificial urbano, Paraná, Brasil. Revista Brasileira de Biociências 8: 229-237.

Bortolini, J.C., Meurer, T. \& Bueno, N.C. 2010 b. Desmídias (Zygnemaphyceae) do Rio São João,
Parque Nacional do Iguaçu, Paraná, Brasil. Hoehnea 37: 293-313.

Cecy, I.I.T., Silva, S.R.V.F. \& Boccon, R. 1997. Fitoplâncton da represa do rio Passaúna, município de Araucária, Estado do Paraná. I - Divisão Chlorophyta - Família Desmidiaceae. Estudos de Biologia 41: 5-32.

Dajoz, R. 2005. Princípios de Ecologia. Artmed, Porto Alegre.

Felisberto, S.A. \& Rodrigues, L. 2004. Periphytic desmids in Corumbá Reservoir, Goiás, Brazil: Genus Cosmarium Corda. Brazilian Journal of Biology 64: 141-150.

Felisberto, S.A. \& Rodrigues, L. 2005. Influência do gradiente longitudinal (rio-barragem) na similaridade das comunidades de desmídias perifíticas. Revista Brasileira de Botânica 28: 241-254.

Felisberto, S.A. \& Rodrigues, L. 2008. Desmidiaceae, Gonatozygaceae e Mesotaeniaceae na comunidade perifítica do reservatório de Salto do Vau (Bacia do rio Iguaçu, PR). Hoehnea 35: 235-254.

Felisberto, S.A. \& Rodrigues, L. 2010. Cosmarium (Desmidiaceae, Zygnemaphyceae) da ficoflórula perifítica do reservatório de Rosana, bacia do rio Paranapanema, Paraná/São Paulo, Brasil. Hoehnea 37: 267-292.

Lozovei, A.L. \& Luz, E. 1976. Díptera culicidae em Curitiba e arredores. II. Alimentação. Archives of Biology and Technology 19: 43-84.

Lozovei, A.L. \& Hohmann, E. 1977. Principais gêneros de microalgas em biótopos de larvas de mosquitos de Curitiba, Estado do Paraná - Brasil. III. Levantamento e constatação da ecologia. Acta Biológica Paranaense 6: $123-152$.

Picelli-Vicentim, M.M., Treuersch, M. \& Domingues, L.L. 2001. Fitoplâncton da represa do Passaúna, Estado do Paraná, Brasil. Hoehnea 28: 53-76.

Prescott, G.W., Croasdale, H.T., Vinyard, W.C. \& Bicudo, C.E.M. 1981. A synopsis of North American Desmids; Part II. Desmidiaceae: Placodermae. University of Nebraska Press, Lincoln.

Silva, S.R.V.F. \& Cecy, I.I.T. 2004. Desmídias (Zygnemaphyceae) da área de abrangência da Usina Hidrelétrica de Salto Caxias, Paraná, Brasil, I: Gênero Cosmarium. Iheringia, série Botânica 59: 13-26. 